\title{
Association study of frameshift and splice variant polymorphisms with risk of idiopathic recurrent pregnancy loss
}

\author{
HYUN AH LEE ${ }^{1 *}$, EUN HEE AHN ${ }^{2 *}$, JI HYANG KIM ${ }^{2}$, JUNG OH KIM ${ }^{1}$, CHANG SOO RYU $^{1}$, \\ JEONG YONG LEE ${ }^{1}$, SUNG HWAN CHO ${ }^{1}$, WOO SIK LEE ${ }^{3}$ and NAM KEUN KIM ${ }^{1}$
}

\author{
${ }^{1}$ Department of Biomedical Science, College of Life Science, CHA University, Seongnam, Gyeonggi 13488; \\ ${ }^{2}$ Department of Obstetrics and Gynecology, CHA Bundang Medical Center, School of Medicine, CHA University, Seongnam, \\ Gyeonggi 13496; ${ }^{3}$ Fertility Center of CHA Gangnam Medical Center, CHA University, Seoul 06135, Republic of Korea
}

Received November 10, 2017; Accepted May 10, 2018

DOI: $10.3892 / \mathrm{mmr} .2018 .9202$

\begin{abstract}
Recurrent pregnancy loss (RPL) is defined as $\geq 2$ consecutive pregnancy losses, and can be caused by various factors, including genetics, chromosomal abnormalities, thrombophilia, immune disorders, nutritional factors, environmental factors, psychological stress or maternal infections; however, as many as 50\% of RPL cases are idiopathic. In the present study, the role of genetic polymorphisms in RPL was investigated. Four gene polymorphisms were selected by whole exome sequencing, including membrane spanning 4-domains A14 (MS4A14)D $>$ I (rs3217518), solute carrier family 2 member 7 (SLC2A7)D $>\mathrm{I}$ (rs60746313), pregnancy specific $\beta$-1-glycoprotein 9 (PSG9)C $>\mathrm{T}$ (rs3746297) and ATP binding cassette subfamily B member 5 (ABCB5) $\mathrm{C}>\mathrm{G}$ (rs17143187), and the aim was to investigate their association with RPL in Korean women. Genotyping was performed using polymerase chain reaction-restriction fragment length polymorphism assay. Allele combination analysis revealed that the four-allele combination I-D-T-G, (MS4A14/SLC2A7/PSG9/ABCB5) was associated with a decreased risk for RPL. Interaction analysis demonstrated that the following genotypes: $M S 4 A 14 \mathrm{DI}+\mathrm{II}, S L C 2 A \mathrm{DI}+\mathrm{II}$ and $A B C B 5 \mathrm{CG}+\mathrm{GG}$, were associated with a prothrombin time $\geq 12 \mathrm{sec}$ and with RPL risk. It may be concluded that the four gene polymorphisms do not affect RPL individually, but are associated with RPL when in combination with other
\end{abstract}

Correspondence to: Professor Nam Keun Kim, Department of Biomedical Science, College of Life Science, CHA University, 335 Pankyo-ro, Seongnam, Gyeonggi 13488, Republic of Korea

E-mail: nkkim@cha.ac.kr; namkkim@naver.com

Professor Woo Sik Lee, Fertility Center of CHA Gangnam Medical Center, CHA University, 606-13 Yeoksam-dong, Seoul 06135, Republic of Korea

E-mail:wooslee@cha.ac.kr

*Contributed equally

Key words: recurrent pregnancy loss, frameshift, splice variant, polymorphism genes or blood coagulation factors. Notably, the MS4A14 I allele, with a prothrombin time $\geq 12 \mathrm{sec}$, may be a potential biomarker for diagnosis, prevention and prognosis of RPL.

\section{Introduction}

Recurrent pregnancy loss (RPL) was initially defined as $\geq 3$ consecutive pregnancy losses before 20 weeks of gestation $(1,2)$, but was later redefined by the American Society for Reproductive Medicine as $\geq 2$ consecutive pregnancy losses (3). An estimated 1-5\% of women of reproductive age experience a pregnancy loss, and 10-20\% of pregnancies end in a miscarriage, which frequently occurs in the second or third month of pregnancy $(2,4,5)$. RPL may be caused by genetic disorders or various other factors, including fetal chromosomal abnormalities, uterine anomalies, thrombophilia, endocrine, immune and anatomical disorders, nutritional or environmental factors, psychological stress, or maternal infections (5). However, in as many as $50 \%$ of women who suffer from recurrent miscarriages, the causes are considered idiopathic. RPL is an important reproductive health issue and remains an active field of research (4). In the present study, the potential genetic cause of RPL was investigated. Four candidate genes harboring mutations that have been associated with other diseases were selected at random as they have not been investigated in association with RPL, and their association with RPL in Korean women was assessed.

Frameshift mutations result from insertions or deletions that alter the reading frame, and affect the subsequent coding sequence as well as the stop codon. Therefore, frameshift mutations may result in final polypeptide products with an abnormal length or in nonsense-mediated mRNA decay (6). This type of mutation has been implicated in numerous diseases; for example, Crohn's disease is associated with the nucleotide-binding oligomerization domain 2 3020insC frameshift mutation (7). Alternatively, abnormalities in alternative splicing have also been implicated in various diseases, including cancer (8-10).

Next-generation sequencing (NGS) is a more advanced method of DNA sequencing compared with Sanger sequencing, which permits the sequencing of the entire human genome in 
1 day $(11,12)$. It offers efficient analysis and rapid processing time, thereby reducing the labor and expenses associated with other sequencing options $(13,14)$. NGS is a powerful tool used to study genetic diseases (13-16), and was therefore the technique of choice for this study.

In the present study, frameshift mutations in membrane spanning 4-domains A14 (MS4A14) and solute carrier family 2 member 7 (SLC2A7), and splice variants in pregnancy specific $\beta$-1-glycoprotein 9 (PSG9) and ATP binding cassette subfamily B member 5 ( $A B C B 5$ ) were investigated. These were selected through whole-exome sequencing (WES). To the best of our knowledge, the following four polymorphisms: $M S 4 A 14 \mathrm{D}>\mathrm{I}$ (rs3217518), SLC2A7D>I (rs60746313), $P S G 9 \mathrm{C}>\mathrm{T}$ (rs3746297) and $A B C B 5 \mathrm{C}>\mathrm{G}$ (rs17143187), have not been previously studied in RPL. Therefore, the aim of the study was to examine the association between these four gene polymorphisms and RPL in Korean women.

\section{Materials and methods}

Study population. The study population included 383 female patients with RPL and 276 control women. Patients with RPL were 22-45 years old, with an average age of $33.11 \pm 4.44$ years and a body mass index (BMI) of $21.48 \pm 3.85 \mathrm{~kg} / \mathrm{m}^{2}$. Women in the control group were 20-66 years old, with an average age of $33.09 \pm 5.68$ years and a BMI of $21.31 \pm 3.30 \mathrm{~kg} / \mathrm{m}^{2}$.

Blood samples were collected from patients with RPL and control women between March 1999 and February 2012 at the Department of Obstetrics and Gynecology and the Fertility Center of CHA Bundang Medical Center (Seongnam, Korea). The study was approved by the Institutional Review Board of CHA Bundang Medical Center (IRB number: BD2010-123D) and written informed consent was provided by all patients. Women in the control group had regular menstrual cycles, a history of $\geq 1$ naturally-conceived pregnancy, no history of pregnancy losses and a normal karyotype $(46, \mathrm{XX})$. Women were diagnosed with RPL if they had a history of $\geq 2$ consecutive spontaneous pregnancy losses. Before week 20 of gestation, ultrasound and/or physical examinations were performed and human gonadotropic hormone levels were assessed. The average gestational age at the time of miscarriage was $7.35 \pm 1.93$ weeks, and overall patients had $3.28 \pm 1.84$ miscarriages.

Patients with a history of smoking or alcohol abuse, or whose miscarriages were attributed to infection or anatomical, hormonal, chromosomal, autoimmune or thrombotic causes were excluded from the study. Anatomical causes of miscarriage were determined using hysterosalpingography, hysteroscopy, computerized tomographic scanning or magnetic resonance imaging, to identify intrauterine adhesion, septate uterus or uterine fibroids. Hormonal causes of miscarriage included hyperprolactinemia, luteal insufficiency and thyroid disease; these were determined by measuring relevant hormone levels in blood samples. The chromosomal causes for miscarriage were assessed by standard chromosome analysis using the G-banding method (17). Miscarriages caused by infection with Ureaplasma urealyticum or Mycoplasma hominis were identified by bacterial culture. The following autoimmune diseases: Lupus and antiphospholipid syndrome, were selected for their strong association with miscarriages; these were identified by measuring lupus anticoagulant and anticardiolipin antibodies. Thrombophilia was defined as a thrombotic disorder associated with miscarriages, and was identified by protein $\mathrm{C}$ and protein $\mathrm{S}$ deficiency, and presence of anti- $\beta-2$ glycoprotein.

Genotyping. Genomic DNA was extracted from peripheral blood of each study participant using the G-DEX DNA extraction kit (Intron Biotechnology, Inc., Seongnam, Korea). Macrogen, Inc. (Seoul, Korea) was commissioned to perform NGS of 20 patients with RPL. NGS was conducted using a HiSeq Instrument (Macrogen, Inc., Seoul, Korea) and paired-end sequences produced by a HiSeq Instrument were first mapped to the human genome using the mapping program 'BWA' (version 0.7.12) (https://sourceforge. net/projects/bio-bwa/files/). Based on the BAM file previously generated, variant genotyping for each sample was performed with Haplotype Caller of GATK (Broad Institute, Cambridge, MA, USA). Then, an in-house program and SnpEff (snpeff.sourceforge.net/) was applied to filter additional databases, including ESP6500 (https://esp.gs.washington. edu/), ClinVar (https://www.ncbi.nlm.nih.gov/clinvar/), and dbNSFP2.9 (https://sites.google. com/site/jpopgen/dbNSFP). WES statistical analyses were also conducted by Macrogen, Inc. The frameshift and splice variants genes were identified from the human genome single nucleotide polymorphism (SNP) database (http://www.ncbi.nlm.nih.gov/snp), and selected from the WES statistical list. The four polymorphisms selected were as follows: $M S 4 A 14 \mathrm{D}>\mathrm{I}$ (rs3217518), $S L C 2 A 7 \mathrm{D}>\mathrm{I}$ (rs60746313), PSG9C $>\mathrm{T}$ (rs3746297) and $A B C B 5 C>\mathrm{G}$ (rs17143187). The four SNPs were genotyped using polymerase chain reaction-restriction fragment length polymorphism (PCR-RFLP) analysis; the primers, PCR conditions and restriction enzymes used, are detailed in Table I (18).

The MS4A14D>I polymorphism was amplified using forward (5'-TTGGATGGAGGGAAAGGTGTG-3') and reverse (5'-TTTTGCCGTGAAGGGAGCT-3') primers, and was amplified by the Solg ${ }^{\text {TM }}$ 2X h-Taq PCR Pre-mix (SolGent co., Ltd., Daejeon, Korea) under the following conditions: $95^{\circ} \mathrm{C}$ for $15 \mathrm{~min} ; 35$ cycles of denaturation at $95^{\circ} \mathrm{C}$ for $30 \mathrm{sec}$, annealing at $55^{\circ} \mathrm{C}$ for $30 \mathrm{sec}$, and extension at $72^{\circ} \mathrm{C}$ for $30 \mathrm{sec}$; and a final extension at $72^{\circ} \mathrm{C}$ for $5 \mathrm{~min}$. The PCR products were digested with the restriction enzyme TspRI (New England BioLabs, Inc., Ipswich, MA, USA) at $65^{\circ} \mathrm{C}$ for $16 \mathrm{~h}$.

The $S L C 2 A 7 \mathrm{D}>\mathrm{I}$ polymorphism was amplified using forward (5'-AAGATGGCGGCTACCTTC-3') and reverse (5'-CTACAACCTCTCTGTGGTCA-3') primers, and was amplified by PCR under the following conditions: $95^{\circ} \mathrm{C}$ for $15 \mathrm{~min} ; 35$ cycles of denaturation at $95^{\circ} \mathrm{C}$ for $30 \mathrm{sec}$, annealing at $53^{\circ} \mathrm{C}$ for $30 \mathrm{sec}$, and extension at $72^{\circ} \mathrm{C}$ for $30 \mathrm{sec}$; and a final extension at $72^{\circ} \mathrm{C}$ for $5 \mathrm{~min}$. The genotypes of the amplified products were identified by electrophoretic separation on a $5 \%$ agarose gel using EcoDye ${ }^{\mathrm{TM}}$ Nucleic Acid Staining Solution (BioFact Co., Ltd., Daejeon, Korea).

The $P S G 9 \mathrm{C}>\mathrm{T}$ polymorphism was amplified using forward (5'-GTAATGGTAGAGGTCCGTCA-3') and reverse (5'-CGT GTGTGTATCTTCAAGGC-3') primers, and was amplified by PCR under the following conditions: $95^{\circ} \mathrm{C}$ for $15 \mathrm{~min}$; 
35 cycles of denaturation at $95^{\circ} \mathrm{C}$ for $30 \mathrm{sec}$, annealing at $57^{\circ} \mathrm{C}$ for $30 \mathrm{sec}$, and extension at $72^{\circ} \mathrm{C}$ for $30 \mathrm{sec}$; and a final extension at $72^{\circ} \mathrm{C}$ for $5 \mathrm{~min}$. The PCR products were digested with the restriction enzyme $B f a \mathrm{I}$ (New England BioLabs, Inc.) at $37^{\circ} \mathrm{C}$ for $16 \mathrm{~h}$.

The $A B C B 5 \mathrm{C}>\mathrm{G}$ polymorphism was amplified using forward (5'-GAGAAAGGAAGCAGTTGG-3') and reverse (5'-TAGTTCCCTCTTTCCCAC-3') primers, and was amplified by PCR under the following conditions: $95^{\circ} \mathrm{C}$ for $5 \mathrm{~min}$; 35 cycles of denaturation at $95^{\circ} \mathrm{C}$ for $30 \mathrm{sec}$, annealing at $52^{\circ} \mathrm{C}$ for $30 \mathrm{sec}$, extension at $72^{\circ} \mathrm{C}$ for $30 \mathrm{sec}$; and a final extension at $72^{\circ} \mathrm{C}$ for $5 \mathrm{~min}$. The PCR products were digested with the restriction enzyme DdeI (Enzynomics, Daejeon, Korea) at $37^{\circ} \mathrm{C}$ for $16 \mathrm{~h}$.

To validate the PCR-RFLP analysis, DNA sequencing was performed on randomly selected samples $(\sim 20 \%$ of total samples), using a BigDye ${ }^{\mathrm{TM}}$ Terminator v3.1 Cycle Sequencing kit (Applied Biosystems; Thermo Fisher Scientific, Inc.), ABI 3730xL DNA Analyzer (Applied Biosystems; Thermo Fisher Scientific, Inc.). PCR-RFLP genotyping was $100 \%$ concordant with DNA sequencing.

Laboratory tests. Plasma homocysteine, folate, total cholesterol, uric acid, blood urea nitrogen (BUN) and creatinine were measured in blood samples collected from patients with RPL after $12 \mathrm{~h}$ of fasting. Homocysteine was measured by IMx fluorescent polarizing immunoassay using the Abbott IMx analyzer (Abbott Pharmaceutical Co. Ltd., Lake Bluff, IL, USA). Folic acid was determined with a radioassay kit (ACS:180; Bayer AG, Leverkusen, Germany). Total cholesterol, uric acid, BUN and creatinine were measured using commercially available enzymatic colorimetric tests of the MODULAR PRE ANALYTICS PLUS system (Roche Diagnostics GmbH, Mannheim. Germany). Platelet (PLT) and white blood cell (WBC) counts were measured using the Sysmex XE-2100 Automated Hematology system (Sysmex Corporation, Kobe, Japan). Prothrombin time (PT) and activated partial thromboplastin time (aPTT) were measured with the ACL TOP automated photo-optical coagulometer (Mitsubishi Gas Chemical Company, Inc., Tokyo, Japan). Blood was collected from the control group by venipuncture on the second or third day of the menstrual cycle for the measurement of FSH, LH, E2, TSH, and prolactin levels. Serum was prepared as previously described (19) and hormone levels were determined using either radioimmunoassays [E2 (cat. no. A21854), TSH (cat. no. IM3712) and PRL (cat. no. IM2121); Beckman Coulter, Inc., Brea, CA, USA], or enzyme immunoassays using IMMULITE ${ }^{\circledR} 1000$ Systems (FSH and LH; Siemens AG, Munich, Germany) according to the manufacturer's protocols.

Flow cytometric analysis of cluster of differentiation $(C D) 56^{+}$ natural killer cells. For cell surface marker staining, peripheral blood samples $(50 \mu 1)$ were mixed with monoclonal anti-CD56 ${ }^{+}$antibodies labeled with fluorescein isothiocyanate (cat. no. 340417, BD Biosciences, Franklin Lakes, NJ, USA) to a ratio of 5:2, for $15 \mathrm{~min}$ at room temperature. A total of $450 \mu 1$ 1X BD FACS ${ }^{\mathrm{TM}}$ lysing solution (cat. no. 349202, BD Biosciences) was added followed by gentle vortexing and two washes with $2 \mathrm{ml}$ fluorescence-activated cell sorting buffer 
Table II. Clinical characteristics of patients with RPL vs. controls.

\begin{tabular}{|c|c|c|c|}
\hline Parameter & Control $n=276(n=$ in each parameter $)$ & RPL n=383 & $\mathrm{P}$ \\
\hline Age (years) & $33.09 \pm 5.68$ & $33.11 \pm 4.44$ & $0.966^{\mathrm{a}}$ \\
\hline BMI $\left(\mathrm{kg} / \mathrm{m}^{2}\right)$ & $21.31 \pm 3.30$ & $21.48 \pm 3.85$ & $0.304^{\mathrm{b}}$ \\
\hline Previous pregnancy losses (no.) & NA & $3.28 \pm 1.84$ & \\
\hline Live births (no.) & $1.73 \pm 0.72$ & NA & \\
\hline Gestational weeks & $39.30 \pm 1.68$ & $7.35 \pm 1.93$ & $<0.0001^{\mathrm{a}}$ \\
\hline $\mathrm{FSH}(\mathrm{mIU} / \mathrm{ml})$ & $8.13 \pm 2.86(110)$ & $7.54 \pm 10.57(195)$ & $<0.0001^{b}$ \\
\hline $\mathrm{E} 2(\mathrm{pg} / \mathrm{ml})$ & $25.87 \pm 14.76(110)$ & $35.36 \pm 29.00(166)$ & $0.002^{b}$ \\
\hline LH (mIU/ml) & $3.28 \pm 1.71(110)$ & $6.33 \pm 12.15(196)$ & $<0.0001^{b}$ \\
\hline $\mathrm{TSH}(\mu \mathrm{IU} / \mathrm{ml})$ & - & $2.19 \pm 1.56(211)$ & \\
\hline Prolactin (ng/ml) & - & $15.61 \pm 12.92(206)$ & \\
\hline $\mathrm{CD}^{2} 6^{+} \mathrm{NK}$ cells $(\%)$ & - & $18.36 \pm 8.02(131)$ & \\
\hline Hematocrit (\%) & $35.35 \pm 4.24(214)$ & $37.31 \pm 3.38(203)$ & $<0.0001^{b}$ \\
\hline $\operatorname{PLT}\left(10^{3}\right.$ platelets $\left./ \mu 1\right)$ & $235.37 \pm 64.08(221)$ & $256.31 \pm 58.83(203)$ & $0.001^{\mathrm{a}}$ \\
\hline PT (sec) & $11.58 \pm 3.14(64)$ & $11.59 \pm 0.86(206)$ & $<0.0001^{b}$ \\
\hline aPTT (sec) & $30.79 \pm 4.64(105)$ & $32.27 \pm 4.33(208)$ & $0.006^{\mathrm{a}}$ \\
\hline Homocysteine $(\mu \mathrm{mol} / \mathrm{l})$ & - & $6.96 \pm 2.10(278)$ & \\
\hline Folate $(\mathrm{ng} / \mathrm{ml})$ & $13.71 \pm 8.37(19)$ & $14.19 \pm 12.01(220)$ & $0.865^{\mathrm{a}}$ \\
\hline BUN (mg/dl) & $8.07 \pm 2.02(41)$ & $9.96 \pm 2.74(196)$ & $<0.0001^{b}$ \\
\hline Creatinine (mg/dl) & $0.69 \pm 0.08(41)$ & $0.72 \pm 0.12(195)$ & $0.056^{\mathrm{b}}$ \\
\hline Total cholesterol (mg/dl) & $239.00 \pm 85.19(15)$ & $187.59 \pm 49.67(178)$ & $0.004^{b}$ \\
\hline Uric acid (mg/dl) & $4.19 \pm 1.44(10)$ & $3.80 \pm 0.84(175)$ & $0.361^{\mathrm{b}}$ \\
\hline
\end{tabular}

Bold text indicate significant P-values. aPTT, activated partial thromboplastin time; BMI, body mass index; BUN, blood urea nitrogen; E2, estradiol; FSH, follicle stimulating hormone; LH, luteinizing hormone; NA, not applicable; PLT, platelet count; PT, prothrombin time; TSH, thyroid-stimulating hormone. All data are presented as the means \pm standard deviation. ${ }^{a}$ Fisher's exact test; ${ }^{b}$ Mann-Whitney test.

(PBS supplemented with $1 \%$ bovine serum albumin and $0.01 \%$ sodium azide; Lonza Group, Ltd., Basel, Switzerland). Cells were fixed in $200 \mathrm{ml}$ 1\% paraformaldehyde (Sigma-Aldrich; Merck KGaA, Darmstadt, Germany) at $30 \mathrm{~min}$ in $4^{\circ} \mathrm{C}$ and washed with BD Perm/Wash ${ }^{\mathrm{TM}}$ buffer (cat. no. 554723, BD Biosciences) prior to acquisition on a BD FACSCalibur (BD Biosciences) (20,21). The data were analyzed using Cell Quest software (BD Biosciences).

Statistical analysis. The gene frequencies of MS4A14, $S L C 2 A 7, P S G 9$ and $A B C B 5$ in patients and controls were assessed by logistic regression, Fisher's exact test and Mann-Whitney test. All genotype frequencies followed the Hardy-Weinberg equilibrium (HWE). The association between the MS4A14, SLC2A7, PSG9 and ABCB5 gene polymorphisms and RPL risk factors were examined by odds ratio (OR), adjusted odds ratio (AOR) and 95\% confidence intervals (CIs). Data are presented as the means \pm standard deviation. $\mathrm{P} \leq 0.05$ was considered to indicate a statistically significant difference. The correlations of each genotype or allele with the proportion of NK cells and plasma Hcy, folate, total cholesterol, and uric acid levels were assessed by the Kruskal-Wallis and Mann-Whitney tests. The false discovery rate (FDR) was used for multiple comparisons correction. An FDR adjusted $\mathrm{P}<0.05$ (q-value) was deemed statistically significant (22). MedCalc version 12.1.4 (MedCalc Software bvba, Ostend, Belgium) or GraphPad Prism version 4.0 (GraphPad Software, Inc., La Jolla, CA, USA) were used for statistical analysis. The HAPSTAT version 3.0 (www.bios. unc.edu/ lin/hapstat/) was used to estimate the frequency of the polymorphic haplotype.

\section{Results}

Study population. In the present study, patients with RPL and control women were compared. The clinical characteristics of the two study groups are summarized in Table II. There was a significant difference between patients with RPL and control women for several of the parameters tested. The PLT values were significantly higher in the RPL patient group than in the control group. Furthermore, LH values were significantly higher in the RPL patient group than in the control group.

Combined effects between clinical factors and gene polymorphism. Interaction analysis was performed to evaluate the association between adjusted factors, such as age and the different gene polymorphisms; the results are presented in Table III. The MS4A14 DI+II genotype was associated with $\mathrm{PT} \geq 12 \sec (\mathrm{AOR}=3.575 ; 95 \% \mathrm{CI}=1.115-11.464)$ and $\mathrm{aPTT} \leq 22.1$ $\sec (\mathrm{AOR}=0.453 ; 95 \% \mathrm{CI}=0.211-0.973)$. The $S L C 2 A \mathrm{DI}+\mathrm{II}$ genotype was associated with $\mathrm{PT} \geq 12 \sec (\mathrm{AOR}=6.517 ; 95 \%$ $\mathrm{CI}=1.783-23.825)$. The PSG9 CT+TT genotype was associated with $\mathrm{PLT} \geq 279 \times 10^{3} / \mu 1 \quad(\mathrm{AOR}=2.069 ; 95 \% \mathrm{CI}=1.079-3.967)$ and $\mathrm{aPTT} \leq 22.1 \mathrm{sec}(\mathrm{AOR}=0.390 ; 95 \% \mathrm{CI}=0.172-0.881)$. The $A B C B 5 \mathrm{CG}+\mathrm{GG}$ genotype was associated with $\mathrm{PT} \geq 12 \mathrm{sec}$ 


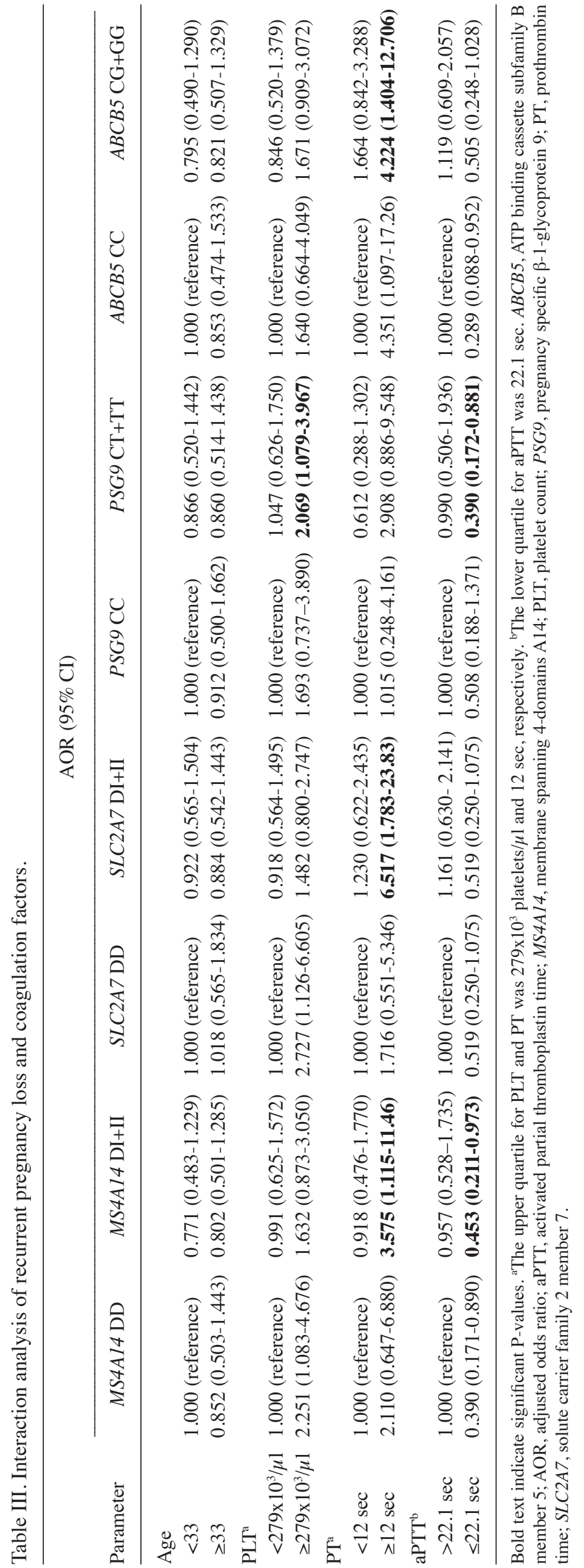


Table IV. Genotype frequencies in patients with RPL and controls.

\begin{tabular}{|c|c|c|c|c|c|}
\hline Genotype & Control $(\%) n=276$ & $\operatorname{RPL}(\%) \mathrm{n}=383$ & $\operatorname{AOR}(95 \% \mathrm{CI})^{\mathrm{a}}$ & $\mathrm{P}^{\mathrm{b}}$ & $q^{c}$ \\
\hline \multicolumn{6}{|l|}{ MS4A14 (rs3217518) } \\
\hline DD & $92(33.3)$ & $141(36.8)$ & 1.000 (reference) & & \\
\hline DI & $139(50.4)$ & $188(49.1)$ & $0.882(0.627-1.242)$ & 0.473 & 0.785 \\
\hline II & $45(16.3)$ & $54(14.1)$ & $0.770(0.478-1.239)$ & 0.281 & 0.562 \\
\hline Dominant (DD vs. DI+II) & & & $0.855(0.617-1.183)$ & 0.344 & 0.582 \\
\hline Recessive (DD+DI vs. II) & & & $0.827(0.537-1.273)$ & 0.388 & 0.746 \\
\hline HWE P & 0.535 & & 0.492 & & \\
\hline \multicolumn{6}{|l|}{ SLC2A7 (rs60746313) } \\
\hline $\mathrm{DD}$ & $74(26.8)$ & $112(29.2)$ & 1.000 (reference) & & \\
\hline DI & $148(53.6)$ & $202(52.7)$ & $0.912(0.635-1.311)$ & 0.619 & 0.785 \\
\hline II & $54(19.6)$ & $69(18.0)$ & $0.854(0.538-1.356)$ & 0.504 & 0.672 \\
\hline Dominant (DD vs. DI+II) & & & $0.895(0.633-1.264)$ & 0.528 & 0.582 \\
\hline Recessive (DD+DI vs. II) & & & $0.906(0.610-1.346)$ & 0.625 & 0.746 \\
\hline HWE P & 0.194 & 0.181 & & & \\
\hline \multicolumn{6}{|l|}{ PSG9 (rs3746297) } \\
\hline $\mathrm{CC}$ & $72(26.1)$ & $108(28.2)$ & 1.000 (reference) & & \\
\hline $\mathrm{CT}$ & $149(54.0)$ & $195(50.9)$ & $0.891(0.616-1.289)$ & 0.540 & 0.785 \\
\hline TT & $55(19.9)$ & $80(20.9)$ & $0.990(0.627-1.562)$ & 0.964 & 0.672 \\
\hline Dominant (CC vs. CT+TT) & & & $0.906(0.639-1.286)$ & 0.582 & 0.582 \\
\hline Recessive (CC+CT vs. TT) & & & $1.066(0.724-1.570)$ & 0.746 & 0.746 \\
\hline HWE P & 0.164 & 0.642 & & & \\
\hline \multicolumn{6}{|l|}{$A B C B 5$ (rs17143187) } \\
\hline $\mathrm{CC}$ & $74(26.8)$ & $113(29.5)$ & 1.000 (reference) & & \\
\hline $\mathrm{CG}$ & $133(48.2)$ & $194(50.7)$ & $0.950(0.658-1.371)$ & 0.785 & 0.785 \\
\hline GG & $69(25.0)$ & $76(19.8)$ & $0.727(0.469-1.129)$ & 0.156 & 0.562 \\
\hline Dominant (CC vs. $\mathrm{CG}+\mathrm{GG})$ & & & $0.872(0.618-1.232)$ & 0.438 & 0.582 \\
\hline Recessive (CC+CG vs. GG) & & & $0.745(0.514-1.079)$ & 0.120 & 0.480 \\
\hline HWE P & 0.551 & 0.658 & & & \\
\hline
\end{tabular}

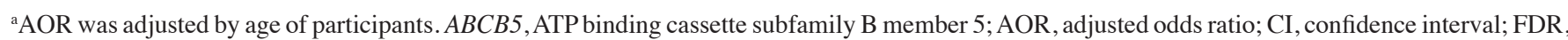
false discovery rate; HWE, Hardy-Weinberg equilibrium; MS4A14, membrane spanning 4-domains A14; PSG9, pregnancy specific $\beta$-1-glycoprotein 9; RPL, recurrent pregnancy loss; $S L C 2 A 7$, solute carrier family 2 member $7 .{ }^{b}$ Fisher's exact test; ${ }^{c}$ FDR-adjusted P-value.

(AOR=4.224; 95\% CI=1.404-12.706). The AOR between the two different gene polymorphisms and PT are summarized in Fig. 1A and B. Overall, these genotypes appeared to be associated with coagulation indicators.

Genotype frequencies of the VEGF polymorphisms. The genotype frequencies of the four selected gene polymorphisms in patients with RPL and normal women are shown in Table IV. According to the results, there was no difference in the frequency of these genotypes between the two study populations, with respect to these polymorphisms. The genotypes between the two groups did not differ with respect to the number of pregnancy losses either, regardless as to whether normal women did not experience pregnancy loss (data not shown). In addition, to determine if various allele combinations were associated with the prevalence of RPL, allele combination analyses were performed with two, three and four allele combinations. The four-allele combination data are presented in Table V (data not shown for two and three allele combinations). Amongst all possible allele combinations of the four genes, MS4A14I/SLC2A7D/PSG9T/ABCB5G was associated with decreased $\mathrm{RPL}$ risk $(\mathrm{OR}=0.448 ; 95 \%$ $\mathrm{CI}=0.223-0.901 ; \mathrm{P}=0.033)$.

Genotype combination analysis. Finally, genotype combination analysis was performed. The following combinations were significantly associated with decreased RPL occurrence: $M S 4 A 14 \mathrm{II} / P S G 9 \mathrm{CT}(\mathrm{OR}=0.446 ; 95 \% \mathrm{CI}=0.200-0.995$; $\mathrm{P}=0.049), \quad M S 4 A 14 \mathrm{II} / A B C B 5 \mathrm{CG} \quad(\mathrm{OR}=0.397 ; 95 \%$ $\mathrm{CI}=0.185-0.851 ; \mathrm{P}=0.018), S L C 2 A 7 \mathrm{DI} / A B C B 5 \mathrm{GG}(\mathrm{OR}=0.485$; $95 \% \mathrm{CI}=0.240-0.981 ; \mathrm{P}=0.044)$ and $S L C 2 A 7 \mathrm{II} / A B C B 5 \mathrm{CC}$ $(\mathrm{OR}=0.376 ; 95 \% \mathrm{CI}=0.152-0.932 ; \mathrm{P}=0.035)$. A summary of the results is shown in Table VI.

\section{Discussion}

In the present study, the association between four gene polymorphisms, namely $M S 4 A 14 \mathrm{D}>\mathrm{I}$ (rs3217518), SLC2A7D >I (rs60746313), PSG9C $>\mathrm{T}$ (rs3746297) and $A B C B 5 \mathrm{C}>\mathrm{G}$ (rs17143187), and RPL were examined. These frameshift 
Table V. Allele combination analysis in patients with RPL and controls.

\begin{tabular}{|c|c|c|c|c|c|}
\hline Allele combination & Controls $\left(2 \mathrm{n}^{\mathrm{a}}=552 ;\right.$ frequency, $\left.\%\right)$ & $\operatorname{RPL}(2 n=766)$ & OR $(95 \% \mathrm{CI})$ & $\mathrm{P}^{\mathrm{b}}$ & $q^{c}$ \\
\hline \multicolumn{6}{|c|}{ MS4A14/SLC2A7/PSG9/ABCB5 } \\
\hline D-D-C-C & $51(9.2)$ & $82(10.7)$ & 1.000 (reference) & & \\
\hline D-D-C-G & $39(7.1)$ & $58(7.6)$ & $0.925(0.541-1.581)$ & 0.786 & 0.983 \\
\hline D-D-T-C & $45(8.1)$ & $72(9.4)$ & $0.995(0.597-1.659)$ & 1.000 & 1.000 \\
\hline D-D-T-G & $41(7.4)$ & $57(7.5)$ & $0.865(0.508-1.472)$ & 0.684 & 0.983 \\
\hline D-I-C-C & $49(8.8)$ & $52(6.8)$ & $0.660(0.391-1.115)$ & 0.142 & 0.710 \\
\hline D-I-C-G & $31(5.6)$ & $50(6.5)$ & $1.003(0.568-1.771)$ & 1.000 & 1.000 \\
\hline D-I-T-C & $28(5.0)$ & $58(7.6)$ & $1.288(0.728-2.280)$ & 0.392 & 0.983 \\
\hline D-I-T-G & $40(7.2)$ & $40(5.2)$ & $0.622(0.355-1.090)$ & 0.116 & 0.710 \\
\hline I-D-C-C & $21(3.9)$ & $34(4.5)$ & $1.007(0.527-1.923)$ & 1.000 & 1.000 \\
\hline I-D-C-G & $36(6.6)$ & $51(6.7)$ & $0.881(0.508-1.530)$ & 0.674 & 0.983 \\
\hline I-D-T-C & $37(6.8)$ & $54(7)$ & $0.908(0.526-1.566)$ & 0.781 & 0.983 \\
\hline I-D-T-G & $25(4.6)$ & $18(2.3)$ & $0.448(0.223-0.901)$ & 0.033 & 0.495 \\
\hline I-I-C-C & $31(5.6)$ & $44(5.7)$ & $0.883(0.496-1.573)$ & 0.768 & 0.983 \\
\hline I-I-C-G & $35(6.3)$ & $40(5.2)$ & $0.711(0.401-1.260)$ & 0.246 & 0.923 \\
\hline I-I-T-C & $19(3.5)$ & $24(3.1)$ & $0.786(0.392-1.576)$ & 0.591 & 0.983 \\
\hline I-I-T-G & $24(4.3)$ & $32(4.1)$ & $0.829(0.440-1.564)$ & 0.626 & 0.983 \\
\hline
\end{tabular}

${ }^{a} 2$, Total number of alleles. ORs and 95\% CIs of each allele combination were calculated with reference the frequency of D-D-C-C and of all others using Fisher's exact test. ABCB5, ATP binding cassette subfamily B member 5; OR, odds ratio; CI, confidence interval; FDR, false discovery rate; MS4A14, membrane spanning 4-domains A14; PSG9, pregnancy specific $\beta$-1-glycoprotein 9; RPL, recurrent pregnancy loss; SLC2A7, solute carrier family 2 member $7 .{ }^{b}$ Fisher's exact test; ${ }^{c}$ FDR-adjusted P-value.
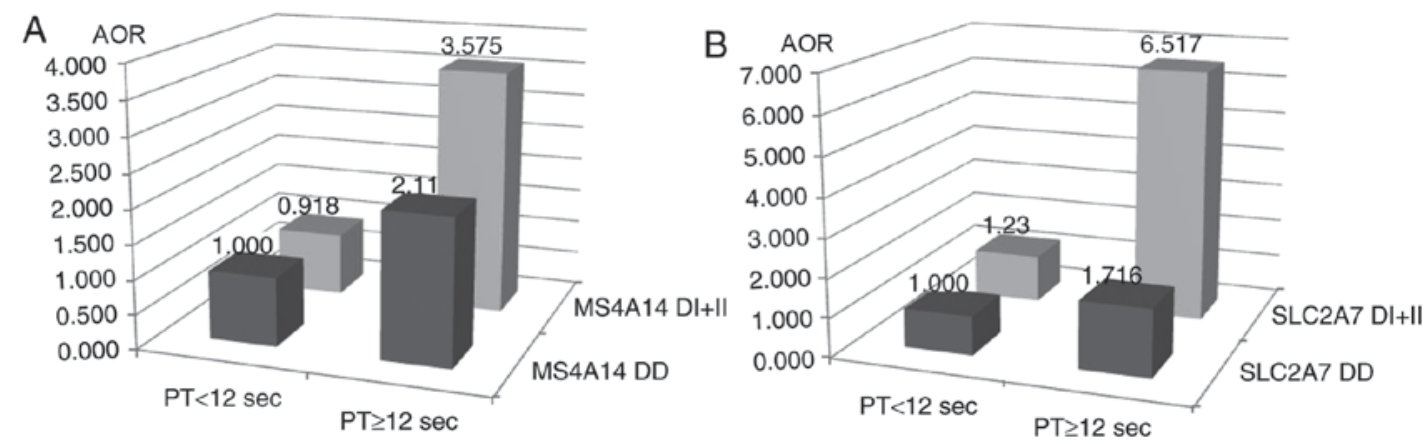

Figure 1. AOR between frameshift and splice variant polymorphisms and PT with respect to RPL risk. The upper quartile for PT was 12 sec in patients with RPL and control women. (A) MS4A14 DI+II genotype was associated with an increased risk of RPL in patients with PT $\geq 12$ sec (AOR=3.575; 95\% CI=1.115-11.464). (B) $S L C 2 A 7 \mathrm{DI}+\mathrm{II}$ genotype was associated with an increased risk of RPL in patients with PT $\geq 12 \mathrm{sec}(\mathrm{AOR}=6.517 ;$ 95\% CI=1.783-23.825). AOR, adjusted odds ratio; CI, confidence interval; MS4A14, membrane spanning 4-domains A14; PT, prothrombin time; RPL, recurrent pregnancy loss; SLC2A7, solute carrier family 2 member 7.

mutations and splice variants have been associated with other diseases, such as colorectal cancer $(23,24)$ and are also implicated in RPL.

The protein encoded by the MS4A14 gene serves an important role in embryo development and fertilization in rats (25). $S L C 2 A 7$, also known as the glucose transporter 7 gene, catalyzes the cellular uptake of sugars. During pregnancy, the transplacental nutrient transport of amino acids, lipids and carbohydrates is important for proper fetal development, and glucose from the maternal circulation is a principal source of energy for the fetus (26). The protein encoded by the PSG9 gene is a member of the pregnancy-specific glycoprotein (PSG) family. In several studies, it was demonstrated that reduced serum concentration of PSG was associated with reduced fetal growth $(27,28)$. The $A B C B 5$ gene is a biomarker for physiological and pathological stem cells, and is a mediator of cell fusion, vasculogenesis and drug efflux (29). A successful pregnancy requires the development of a complex maternal and fetal vascular network that can support the increasing oxygen and metabolic demands of the growing fetus (30). Furthermore, placental development occurs through the vasculogenesis and angiogenesis stage (31). Therefore, it may be hypothesized that a mutation in $A B C B 5$ would influence RPL.

Although the individual gene variations examined in this study were not associated with RPL, gene combinations were demonstrated to be associated with RPL. Allele combination analysis (MS4A14I/SLC2A7D/PSG9T/ABCB5G) and 
Table VI. Gene combination analysis in patients with RPL and controls.

\begin{tabular}{|c|c|c|c|c|c|}
\hline Genotype & Control $(\%) \mathrm{n}=276$ & $\operatorname{RPL}(\%) \mathrm{n}=383$ & AOR $(95 \% \mathrm{CI})$ & $\mathrm{P}^{\mathrm{a}}$ & $q$-value ${ }^{b}$ \\
\hline \multicolumn{6}{|c|}{$M S 4 A 14 / S L C 2 A 7$} \\
\hline $\mathrm{DD} / \mathrm{DD}$ & $28(10.1)$ & $49(12.8)$ & 1.000 (reference) & & \\
\hline $\mathrm{DD} / \mathrm{DI}$ & $45(16.3)$ & $66(17.2)$ & $0.828(0.454-1.510)$ & 0.538 & 0.613 \\
\hline $\mathrm{DD} / \mathrm{II}$ & $19(6.9)$ & $26(6.8)$ & $0.794(0.369-1.708)$ & 0.555 & 0.613 \\
\hline $\mathrm{DI} / \mathrm{DD}$ & $33(12.0)$ & $46(12.0)$ & $0.792(0.415-1.510)$ & 0.478 & 0.613 \\
\hline DI/DI & $80(29.0)$ & $111(29.0)$ & $0.781(0.452-1.351)$ & 0.377 & 0.613 \\
\hline $\mathrm{DI} / \mathrm{II}$ & $26(9.4)$ & $31(8.1)$ & $0.677(0.335-1.370)$ & 0.279 & 0.613 \\
\hline $\mathrm{II} / \mathrm{DD}$ & $13(4.7)$ & $17(4.4)$ & $0.713(0.295-1.725)$ & 0.453 & 0.613 \\
\hline $\mathrm{II} / \mathrm{DI}$ & $23(8.3)$ & $25(6.5)$ & $0.607(0.291-1.269)$ & 0.185 & 0.613 \\
\hline II/II & $9(3.3)$ & $12(3.1)$ & $0.773(0.285-2.094)$ & 0.613 & 0.613 \\
\hline \multicolumn{6}{|c|}{ MS4A14/PSG9 } \\
\hline $\mathrm{DD} / \mathrm{CC}$ & $21(7.6)$ & $39(10.2)$ & 1.000 (reference) & & \\
\hline $\mathrm{DD} / \mathrm{CT}$ & $49(17.8)$ & $70(18.3)$ & $0.782(0.409-1.496)$ & 0.457 & 0.713 \\
\hline $\mathrm{DD} / \mathrm{TT}$ & $22(8.0)$ & $32(8.4)$ & $0.786(0.368-1.681)$ & 0.535 & 0.713 \\
\hline $\mathrm{DI} / \mathrm{CC}$ & $42(15.2)$ & $48(12.5)$ & $0.612(0.312-1.201)$ & 0.153 & 0.408 \\
\hline $\mathrm{DI} / \mathrm{CT}$ & $75(27.2)$ & $102(26.6)$ & $0.759(0.410-1.404)$ & 0.380 & 0.713 \\
\hline $\mathrm{DI} / \mathrm{TT}$ & $22(8.0)$ & $38(9.9)$ & $1.034(0.481-2.223)$ & 0.933 & 0.933 \\
\hline $\mathrm{II} / \mathrm{CC}$ & $9(3.3)$ & $21(5.5)$ & $1.206(0.466-3.122)$ & 0.699 & 0.799 \\
\hline $\mathrm{II} / \mathrm{CT}$ & $25(9.1)$ & $23(6.0)$ & $0.446(0.200-0.995)$ & 0.049 & 0.392 \\
\hline $\mathrm{II} / \mathrm{TT}$ & $11(4.0)$ & $10(2.6)$ & $0.476(0.172-1.318)$ & 0.153 & 0.392 \\
\hline \multicolumn{6}{|c|}{$M S 4 A 14 / A B C B 5$} \\
\hline $\mathrm{DD} / \mathrm{CC}$ & $26(9.4)$ & $44(11.5)$ & 1.000 (reference) & & \\
\hline $\mathrm{DD} / \mathrm{CG}$ & $42(15.2)$ & $67(17.5)$ & $0.955(0.513-1.780)$ & 0.886 & 0.974 \\
\hline $\mathrm{DD} / \mathrm{GG}$ & $24(8.7)$ & $30(7.8)$ & $0.732(0.354-1.514)$ & 0.400 & 0.640 \\
\hline $\mathrm{DI} / \mathrm{CC}$ & $42(15.2)$ & $52(13.6)$ & $0.715(0.378-1.351)$ & 0.301 & 0.640 \\
\hline $\mathrm{DI} / \mathrm{CG}$ & $63(22.8)$ & $107(27.9)$ & $1.010(0.566-1.801)$ & 0.974 & 0.974 \\
\hline $\mathrm{DI} / \mathrm{GG}$ & $34(12.3)$ & $29(7.6)$ & $0.503(0.251-1.007)$ & 0.052 & 0.208 \\
\hline $\mathrm{II} / \mathrm{CC}$ & $6(2.2)$ & $17(4.4)$ & $1.679(0.588-4.799)$ & 0.333 & 0.640 \\
\hline $\mathrm{II} / \mathrm{CG}$ & $28(10.1)$ & $20(5.2)$ & $0.397(0.185-0.851)$ & 0.018 & 0.144 \\
\hline II/GG & $11(4.0)$ & $17(4.4)$ & $0.912(0.370-2.245)$ & 0.841 & 0.974 \\
\hline \multicolumn{6}{|c|}{$S L C 2 A 7 / P S G 9$} \\
\hline $\mathrm{DD} / \mathrm{CC}$ & $17(6.2)$ & $35(9.1)$ & 1.000 (reference) & & \\
\hline $\mathrm{DD} / \mathrm{CT}$ & $43(15.6)$ & $55(14.4)$ & $0.676(0.331-1.380)$ & 0.282 & 0.437 \\
\hline $\mathrm{DD} / \mathrm{TT}$ & $14(5.1)$ & $22(5.7)$ & $0.836(0.340-2.056)$ & 0.696 & 0.696 \\
\hline $\mathrm{DI} / \mathrm{CC}$ & $36(13.0)$ & $48(12.5)$ & $0.657(0.317-1.361)$ & 0.258 & 0.437 \\
\hline $\mathrm{DI} / \mathrm{CT}$ & $81(29.3)$ & $108(28.2)$ & $0.652(0.339-1.252)$ & 0.199 & 0.437 \\
\hline $\mathrm{DI} / \mathrm{TT}$ & $31(11.2)$ & $46(12.0)$ & $0.770(0.366-1.622)$ & 0.492 & 0.562 \\
\hline $\mathrm{II} / \mathrm{CC}$ & $19(6.9)$ & $25(6.5)$ & $0.654(0.283-1.511)$ & 0.320 & 0.437 \\
\hline $\mathrm{II} / \mathrm{CT}$ & $25(9.1)$ & $32(8.4)$ & $0.661(0.300-1.455)$ & 0.304 & 0.437 \\
\hline $\mathrm{II} / \mathrm{TT}$ & $10(3.6)$ & $12(3.1)$ & $0.601(0.216-1.668)$ & 0.328 & 0.437 \\
\hline \multicolumn{6}{|c|}{$S L C 2 A 7 / A B C B 5$} \\
\hline $\mathrm{DD} / \mathrm{CC}$ & $20(7.2)$ & $37(9.7)$ & 1.000 (reference) & & \\
\hline $\mathrm{DD} / \mathrm{CG}$ & $42(15.2)$ & $50(13.1)$ & $0.631(0.319-1.249)$ & 0.186 & 0.372 \\
\hline $\mathrm{DD} / \mathrm{GG}$ & $12(4.3)$ & $25(6.5)$ & $1.090(0.450-2.639)$ & 0.849 & 0.875 \\
\hline $\mathrm{DI} / \mathrm{CC}$ & $36(13.0)$ & $63(16.4)$ & $0.946(0.477-1.877)$ & 0.875 & 0.875 \\
\hline $\mathrm{DI} / \mathrm{CG}$ & $69(25.0)$ & $99(25.8)$ & $0.761(0.406-1.427)$ & 0.395 & 0.632 \\
\hline $\mathrm{DI} / \mathrm{GG}$ & $43(15.6)$ & $40(10.4)$ & $0.485(0.240-0.981)$ & 0.044 & 0.176 \\
\hline $\mathrm{II} / \mathrm{CC}$ & $18(6.5)$ & $13(3.4)$ & $0.376(0.152-0.932)$ & 0.035 & 0.176 \\
\hline $\mathrm{II} / \mathrm{CG}$ & $22(8.0)$ & $45(11.7)$ & $1.118(0.529-2.364)$ & 0.769 & 0.875 \\
\hline II/GG & $14(5.1)$ & $11(2.9)$ & $0.428(0.164-1.117)$ & 0.083 & 0.221 \\
\hline \multicolumn{6}{|c|}{$P S G 9 / A B C B 5$} \\
\hline $\mathrm{CC} / \mathrm{CC}$ & $19(6.9)$ & $29(7.6)$ & 1.000 (reference) & & \\
\hline $\mathrm{CC} / \mathrm{CG}$ & $37(13.4)$ & $50(13.1)$ & $0.865(0.421-1.777)$ & 0.693 & 0.892 \\
\hline
\end{tabular}


Table VI. Continued.

\begin{tabular}{lccrr}
\hline Genotype & Control $(\%) \mathrm{n}=276$ & RPL $(\%) \mathrm{n}=383$ & AOR $(95 \% \mathrm{CI})$ & $\mathrm{P}^{\mathrm{a}}$ \\
\hline CC/GG & $16(5.8)$ & $29(7.6)$ & $1.206(0.518-2.805)$ & 0.665 \\
CT/CC & $41(14.9)$ & $59(15.4)$ & $0.915(0.450-1.860)$ & 0.806 \\
CT/CG & $72(26.1)$ & $104(27.2)$ & $0.956(0.496-1.840)$ & 0.892 \\
CT/GG & $36(13.0)$ & $32(8.4)$ & $0.569(0.268-1.209)$ & 0.143 \\
TT/CC & $14(5.1)$ & $25(6.5)$ & $1.259(0.515-3.077)$ & 0.613 \\
TT/CG & $24(8.7)$ & $40(10.4)$ & $1.091(0.501-2.376)$ & 0.892 \\
TT/GG & $17(6.2)$ & $15(3.9)$ & $0.606(0.243-1.513)$ & 0.892 \\
\hline
\end{tabular}

Bold text indicate significant P-values. ABCB5, ATP binding cassette subfamily B member 5; AOR, adjusted odds ratio; CI, confidence interval; FDR false discovery rate; MS4A14, membrane spanning 4-domains A14; PSG9, pregnancy specific $\beta$-1-glycoprotein 9; RPL, recurrent pregnancy loss;

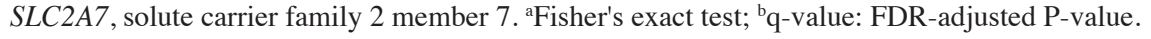

genotype combination analysis (MS4A14II/PSG9CT and $M S 4 A 14 \mathrm{II} / A B C B 5 \mathrm{CG})$ revealed that the I allele affected RPL when the $M S 4 A 14 \mathrm{D}>\mathrm{I}$ polymorphism was present with other genes.

The present study also demonstrated that all the selected gene polymorphisms were associated with RPL when the blood coagulation factors PLT, PT and aPTT were included in the interaction analysis. During pregnancy, fibrinolysis and coagulation must be precisely balanced so that excess fibrin deposition in placental vessels and intravillous spaces does not occur, and to ensure fibrin polymerization and stabilization of the placental basal plate. Defects in this process can have a negative impact on trophoblast transplantation and placenta development, ultimately leading to miscarriage (32). Therefore, if blood coagulation factors deviate from their normal levels this may result in an unsuccessful pregnancy.

The present study has several limitations. Firstly, it is unclear whether these polymorphisms can affect gene transcription and/or translation. Secondly, the study only included Korean women who visited the CHA Bundang Medical Center, and it would be useful to validate the findings in a different cohort. Lastly, the control group size was smaller than the patient group. Nevertheless, to the best of our knowledge, this study is the first of its kind to investigate the association between the gene polymorphisms MS4A14D>I (rs3217518), $S L C 2 A 7 \mathrm{D}>\mathrm{I}$ (rs60746313), PSG9C $>\mathrm{T}$ (rs3746297) and $A B C B 5 C>\mathrm{G}$ (rs17143187), and RPL. These genes have been implicated in cancer and some other diseases, but have not been previously studied in the context of RPL. Therefore, these findings may help to improve our understanding of frameshift mutations and splice variants in pregnancy.

In conclusion, the association between RPL and four gene polymorphisms, MS4A14D>I (rs3217518), SLC2A7D>I (rs60746313), PSG9C $>\mathrm{T}$ (rs3746297) and $A B C B 5 \mathrm{C}>\mathrm{G}$ (rs17143187), was investigated in Korean women. These four polymorphisms were not associated with RPL individually, but were associated with RPL when combined with other genes or when factoring in blood coagulation factors. Notably, the MS4A14 I allele, alongside a PT $\geq 12 \mathrm{sec}$, may be a potential biomarker for the diagnosis, prevention and prognosis of RPL. Further studies are required to clarify the associations between the four gene polymorphisms and RPL in an ethnically diverse cohort.

\section{Acknowledgements}

Not applicable.

\section{Funding}

The present study was partly supported by the Basic Science Research Programs through the National Research Foundation of Korea funded by the Ministry of Education, Science, and Technology (grant no. 2009-0093821, 2015R1D1A1A09057432 and 2017R1D1A1B03031542). The present study was also partly supported by a grant from the Korea Healthcare Technology R\&D Project, Ministry for Health, Welfare \& Family Affairs, Republic of Korea (grant no. HI15C1972010015).

\section{Availability of data and materials}

Not applicable.

\section{Authors' contributions}

WSL and NKK conceived and designed the experiments. HAL, CSR, JYL and JOK performed the experiments. EHA, JHK, CSR, JYL and SHC performed the analysis and interpretation of data for this study. WSL and NKK. prepared reagents/materials/analytical tools for experiments and analysis. HAL and EHA wrote the paper. JHK, SHC, WSL and NKK revised the manuscript for important intellectual information.

\section{Ethics approval and consent to participate}

The study was approved by the Institutional Review Board of CHA Bundang Medical Center (IRB number: BD2010-123D) and written informed consent was provided by all patients.

\section{Patient consent for publication}

Not applicable.

\section{Competing interests}

The authors declare that they have no competing interests. 


\section{References}

1. Hefler LA, Tempfer CB, Unfried G, Schneeberger C, Lessl K, Nagele F and Huber JC: A polymorphism of the interleukin-1beta gene and idiopathic recurrent miscarriage. Fertil Steril 76: 377-379, 2001.

2. Jang HG, Choi Y, Kim JO, Jeon YJ, Rah H, Cho SH, Kim JH, Lee WS and Kim NK: Polymorphisms in tumor necrosis factor-alpha $(-863 \mathrm{C}>\mathrm{A},-857 \mathrm{C}>\mathrm{T}$ and $+488 \mathrm{G}>\mathrm{A})$ are associated with idiopathic recurrent pregnancy loss in Korean women. Hum Immunol 77: 506-511, 2016.

3. Practice Committee of American Society for Reproductive Medicine: Definitions of infertility and recurrent pregnancy loss: a committee opinion. Fertil Steril 99: 63, 2013.

4. Su MT, Lin SH, Lee IW, Chen YC, Hsu CC, Pan HA and Kuo PL: Polymorphisms of endocrine gland-derived vascular endothelial growth factor gene and its receptor genes are associated with recurrent pregnancy loss. Hum Reprod 25: 2923-2930, 2010.

5. Kim HS, Lee BE, Jeon YJ, Rah H, Lee WS, Shin JE, Choi DH and Kim NK: Transcobalamin II (TCN2 $67 \mathrm{~A}>\mathrm{G}$ and TCN2 776C $>$ G) and transcobalamin II receptor (TCblR 1104C $>$ T) polymorphisms in Korean patients with idiopathic recurrent spontaneous abortion. Am J Reprod Immunol 72: 337-346, 2014

6. Altawil AS, Mawlawi HA, Alghamdi KA and Almijmaj FF: A novel homozygous frameshift mutation in exon 2 of LEP gene associated with severe obesity: A case report. Clin Med Insights Pediatr 10: 115-118, 2016

7. Ogura Y, Bonen DK, Inohara N, Nicolae DL, Chen FF, Ramos R, Britton H, Moran T, Karaliuskas R, Duerr RH, et al: A frameshift mutation in NOD2 associated with susceptibility to Crohn's disease. Nature 411: 603-606, 2001.

8. Camacho Londoño J and Philipp SE: A reliable method for quantification of splice variants using RT-qPCR. BMC Mol Biol 17: 8, 2016

9. Furnham N, Ruffle S and Southan C: Splice variants: A homology modeling approach. Proteins 54: 596-608, 2004.

10. Chen J and Weiss WA: Alternative splicing in cancer: Implications for biology and therapy. Oncogene 34: 1-14, 2015.

11. Orzińska A, Guz K, Mikula M, Kulecka M, Kluska A, Balabas A, Pelc-Kłopotowska M, Ostrowski J and Brojer E: A preliminary evaluation of next-generation sequencing as a screening tool for targeted genotyping of erythrocyte and platelet antigens in blood donors. Blood Transfus 16: 285-292, 2017.

12. Behjati S and Tarpey PS: What is next generation sequencing? Arch Dis Child Educ Pract Ed 98: 236-238, 2013.

13. Joensen KG, Engsbro AL $\varnothing$, Lukjancenko O, Kaas RS, Lund O, Westh $\mathrm{H}$ and Aarestrup FM: Evaluating next-generation sequencing for direct clinical diagnostics in diarrhoeal disease. Eur J Clin Microbiol Infect Dis 36: 1325-1338, 2017.

14. Hodzic J, Gurbeta L, Omanovic-Miklicanin E and Badnjevic A: Overview of next-generation sequencing platforms used in published draft plant genomes in light of genotypization of immortelle plant (Helichrysium Arenarium). Med Arch 71: 288-292, 2017

15. Bevilacqua J, Hesse A, Cormier B, Davey J, Patel D, Shankar K and Reddi HV: Clinical utility of a 377 gene custom next-generation sequencing epilepsy panel. J Genet 96: 681-685, 2017.

16. Yoon B, Kim Y-J, Son S-Y, Han K and Park BC: Whole-exome sequencing in Tricho-rhino-phalangeal syndrome (TRPS) type I in a Korean family. Genes Genomics 39: 417-422, 2017.

17. Barch MJ, Knutsen T and Spurbeck JL: The AGT Cytogenetics Laboratory Manual. 3rd ed. Lippincott-Raven, New York, pp481-526, 1997.
18. Cho H-S, Kim W, Choi M-K, Le MT, Choi HJ, Kim J-H, Kim K, Soundrarajan N, Park J-K, Lee Y-M, et al: Effects of natural resistance-associated macrophage protein 1 and toll-like receptor 2 gene polymorphisms on post-weaning piglet survivability. Genes Genomics 38: 171-178, 2016.

19. Choi DH, Kim EK, Kim KH, Lee KA, Kang DW, Kim HY, Bridges P and Ko CM: Expression pattern of endothelin system components and localization of smooth muscle cells in the human pre-ovulatory follicle. Hum Reprod 26: 1171-1180, 2011.

20. Rosen HR, Doherty DG, Madrigal-Estebas L, O'Farrelly C and Golden-Mason L: Pretransplantation CD56(+) innate lymphocyte populations associated with severity of hepatitis $C$ virus recurrence. Liver Transpl 14: 31-40, 2008.

21. Carbone T, Nasorri F, Pennino D, Eyerich K, Foerster S, Cifaldi L, Traidl-Hoffman $\mathrm{C}$, Behrendt $\mathrm{H}$ and Cavani $\mathrm{A}$ : CD56highCD16-CD62L- NK cells accumulate in allergic contact dermatitis and contribute to the expression of allergic responses. J Immunol 184: 1102-1110, 2010.

22. Benjamini Y and Hochberg Y: Controlling the false discovery rate: A practical and powerful approach to multiple testing. J R Stat Soc 57: 289-300, 1995.

23. Yeon SY, Jo YS, Choi EJ, Kim MS, Yoo NJ and Lee SH: Frameshift mutations in repeat sequences of ANK3, HACD4, TCP10L, TP53BP1, MFN1, LCMT2, RNMT, TRMT6, METTL8 and METTL16 genes in colon cancers. Pathol Oncol Res 24: 617-622, 2017.

24. Ling Y, Kuang Y, Chen LL, Lao WF, Zhu YR, Wang LQ and Wang D: A novel RON splice variant lacking exon 2 activates the PI3K/AKT pathway via PTEN phosphorylation in colorectal carcinoma cells. Oncotarget 8: 39101-39116, 2017.

25. Jia XF, Zhou M, Lin JF, Shi WL, Zhang XD and Shi HJ: Role of SP3111 protein in fertilization and early embryo development in mice. Zhonghua Nan Ke Xue 16: 14-19, 2010.

26. Stanirowski PJ, Szukiewicz D, Pyzlak M, Abdalla N, Sawicki W and Cendrowski K: Impact of pre-gestational and gestational diabetes mellitus on the expression of glucose transporters GLUT-1, GLUT-4 and GLUT-9 in human term placenta. Endocrine 55: 799-808, 2017.

27. Moore T and Dveksler GS: Pregnancy-specific glycoproteins: Complex gene families regulating maternal-fetal interactions. Int J Dev Biol 58: 273-280, 2014.

28. Pihl K, Larsen T, Laursen I, Krebs L and Christiansen M: First trimester maternal serum pregnancy-specific beta-1-glycoprotein (SP1) as a marker of adverse pregnancy outcome. Prenat Diagn 29: 1256-1261, 2009.

29. VolpicelliER,Lezcano C,Zhan Q, Girouard SD, Kindelberger DW, Frank MH, Frank NY, Crum CP and Murphy GF: The multidrug-resistance transporter ABCB5 is expressed in human placenta. Int J Gynecol Pathol 33: 45-51, 2014.

30. Geva E, Ginzinger DG, Zaloudek CJ, Moore DH, Byrne A and Jaffe RB: Human placental vascular development: Vasculogenic and angiogenic (branching and nonbranching) transformation is regulated by vascular endothelial growth factor-A, angiopoietin-1, and angiopoietin-2. J Clin Endocrinol Metab 87: 4213-4224, 2002

31. KayisliUA,DemirR,ErgulerGand Arici A:Vasodilator-stimulated phosphoprotein expression and its cytokine-mediated regulation in vasculogenesis during human placental development. Mol Hum Reprod 8: 1023-1030, 2002.

32. Buchholz $\mathrm{T}$ and Thaler CJ: Inherited thrombophilia: Impact on human reproduction. Am J Reprod Immunol 50: 20-32, 2003. 